\title{
Self-reassurance, Self-criticism, and Eye-tracking of Happy Faces
}

Bronislava Strnádelová, Júlia Halamová

Institute of Applied Psychology, Faculty of Social and Economic Sciences, Comenius University, Bratislava, Slovak Republic

\author{
Andrej Mentel \\ Institute of Social Anthropology, Faculty of Social \\ and Economic Sciences, Comenius University, \\ Bratislava, Slovak Republic
}

\begin{abstract}
This study explores the relationship between self-criticism, self-reassurance, and the face scanning patterns participants use to recognize photos of happiness. Forty-two participants were being recorded by eye-trackers while watching photos of happy and neutral facial expressions. Participants also completed the Forms of Self-Criticising/Attacking and Self-Reassuring Scale. The Hated Self score was negatively related to the total fixation duration on the eyes and around the eyes. The Inadequate Self score tended to correlate positively with the total fixation duration time on all examined areas of the face and Reassured Self score tended to correlate positively with the total fixation duration time on the area around the eyes, although none of these correlations appeared to be statistically significant. Being able to distinguish between the more pathological Hated Self form of self-criticism and the less pathological Inadequate Self could improve psychological assessment and intervention evaluations.
\end{abstract}

Key words: emotion, eye-tracking, face, happiness, self-criticism, self-reassurance

\section{Introduction}

\section{Emotion Recognition}

There has long been a debate on the universality (e.g., Ekman, 1972; Izard, 1971; Matsumoto, 2001) and cultural specificities of

Acknowledgement

Writing this work was supported by the VEGA grant agency under Grant 1/0075/19, by Grant mladých UK (Grant number: UK/167/2017), and also by the Slovak Research and Development Agency under the contract No. APVV-14-0431.

Correspondence concerning this article should be addressed to Dr. Julia Halamová, Institute of Applied Psychology, Faculty of Social and Economic Sciences, Comenius University, Mlynské luhy 4, 821 05 Bratislava, Slovak Republic. E-mail: julia.halamova@gmail.com

Received March 13, 2019 recognizing emotions (e.g., Gendron, Roberson, Vyver, \& Barrett, 2014; Jack et al., 2012; Lindquist \& Barrett, 2012; 1971; Russell, 1994). The highest recognition levels are obtained with the expression of happiness (Calvo \& Lundqvist, 2008; Ekman \& Friesen, 1976; Hess, Blairy, \& Kleck, 1997; Russell, 1994). Previous studies have shown that a joyful expression is recognized with greater accuracy and/or speed than are other primary emotions (e.g., Gablíková \& Strnádelová, 2016; Goren \& Wilson, 2006; Leppänen \& Hietanen, 2004; Palermo \& Coltheart, 2004). However, participants who have depression or who are shy, shameful, anxious or have feelings of inadequacy had more difficulty recognizing precisely joyful expressions (e.g., Gotlib, Krasnoperova, Yue, \& Joormann, 2004; Gilbert et al., 2006) than participants who experienced none of these. Wang, $\mathrm{Hu}$, Short, and Fu (2012) assumed that the first category of participants tends to avoid direct eye contact during emotion recognition as the 
participants' shyness scores were negatively correlated with fixation on the eyes. Self-criticism is significantly associated with shyness and shame (Gilbert \& Miles, 2000). According to McEwan et al. (2014), self-critical people generally perceive happy facial expressions as threatening. Previous research (Schultheiss \& Hale, 2007) showed that happy expressions can be problematic because they may be viewed with aversion and as threatening rather than as expressing sympathy or closeness. Self-critical people do not perceive smiles and facial expressions of happiness and compassion as supportive but as unpleasant and even mocking. Similarly, studies based on the concepts of anxiety and social anxiety (see Daly, 1978; Farabee, Holcom, Ramsey, \& Cole, 1993) showed that in social interactions anxious individuals spent less time gazing toward a disagreeing fellow than did socially secure individuals.

In Daly's research (1978) scores by highschool students on a paper-and-pencil test of social anxiety were correlated with eye contact during a videotaped interview. Participants with high levels of anxiety held their gaze for less time overall and for bouts of shorter duration when they were talking. Research findings have supported the idea that self-criticism and a low level of self-reassurance are related to anxiety, shame, feelings of inferiority, or inadequacy (Blatt et al., 1992) and are possible markers of gaze avoidance (e.g., Daly, 1978; Wang, Hu, Short, \& Fu, 2012). Despite confirmation of a relationship between self-criticism on the one hand and depression, anxiety, social anxiety on the other (Blatt et al., 1992; Gilbert, 2011), there is a lack of research on the relationship between gaze (avoidance) and self-criticism/self-reassurance in facial expression recognition.

\section{Eye-Tracking of Happiness Recognition}

There is confusion in the eye-tracking research as to the role the lip and eye regions play in the facial recognition of primary emotions (see e.g., Blais et al., 2012; Pérez-Moreno, Romero-Ferreiro, \& García-Gutiérrez; 2016, Schurgin et al., 2014). Milders, Hietanen, and Leppänen (2011) claimed that happy faces are more frequently detected by healthy individuals using a direct gaze. However, Blais et al. (2012) disagreed and found that the lip area was the most important cue for recognition of both the static and dynamic facial expressions. When happy faces were scanned, there tended to be more fixations on the lip region.

However, Williams et al. (2001) conducted a study examining eye-fixation patterns in order to better understand perceptions of the "true" Duchenne smile. The results indicated that participants' eyes fixated more and for longer on the Duchenne region (e.g., on the crow's feet) of a face with a happy expression than on faces with sad and neutral expressions. This is indicative of a tendency to focus on that specific marker when exposed to a happy expression. Manera et al. (2011) also revealed that participants spent significantly more time on the eye region than on the mouth region, especially when the Duchenne marker and the Lid tightener were activated, than they did in relation to smiles with neutral eyes. This research suggests that healthy individuals are sensitive to the appearance changes created by muscular activation in the eye region when recognizing happiness.

It is assumed that the tendency to be submissive is related to an individual feeling inferior to another in some way and the belief that other people are more competent and valid than the submissive individual (Gilbert \& Allan, 1994). Studies have also demonstrated that people who see themselves as inferior to others tend to adopt submissive behavior (Allan \& Gilbert, 1997; Gilbert \& Allan, 1994) and that submissive behavior is negatively correlated with a fear of negative evaluation, part of selfcriticism (Gilbert, 2000). Gilbert et al. (2004) 
pointed out that self-criticism has two components: "being self-critical", that is overestimating errors and feeling inadequate; and feeling the need to hurt oneself and feeling contempt and self-hate.

We suppose that highly self-critical people with feelings of inadequacy are less dominant and more submissive than less self-critical people or highly self-reassured people. Investigations into the link between self-criticism and submissiveness have shown that submissive individuals avert their gaze from social threats and do not look into the eyes of an individual seen as a social threat (Terburg \& van Honk, 2012). It is believed that highly selfcritical people tend to have low self-reassurance and that people with high self-reassurance tend to be less self-critical (Gilbert, 2010). Given previous findings related to concepts associated with self-criticism, such as anxiety, shame, and non-dominance (Daly, 1978; Terburg \& van Honk, 2012; Wang, Hu, Short, $\& \mathrm{Fu}, 2012$ ), we were interested in the mechanisms underpinning specific patterns in the identification of the emotion of happiness in relation to level of self-criticism and self-reassurance.

We decided to explore the eye-tracking of happy faces, because the emotion of happiness is perceived with obvious barriers or inaccuracies (McEwan et al.; 2014; Schultheiss \& Hale, 2007). We suppose that exactly the smiling expression could evoke the biases and be the significant expression from the list of primary emotions in distinguishing the levels of self-criticism/self-reassurance.

\section{Aim of the Study}

Our goal was to identify the facial points people focus on when observing the facial expression of happiness in relation to their level of self-criticism and self-reassurance.

\section{Hypotheses of the Study}

Based on the previous studies (mainly Daly, 1978; Farabee, Holcom, Ramsey, \& Cole, 1993; Wang, Short, Hu, \& Fu, 2012; Milders, Hietanen, \& Leppänen, 2011; Williams et al., 2011), we expect that:

1) Higher Self-criticism (Inadequate Self and/ or Hated Self score) will predict a lower total fixation time on the eyes when observing the facial expression of happiness.

2) Higher Self-reassurance will predict a higher total fixation time on the eyes when observing the facial expression of happiness.

\section{Method}

\section{Participants}

The research sample consisted of 42 adult participants from Slovakia, (23 women and 19 men; $M=27.48$ years, $S D=13.66)$. The participants were recruited by convenience sampling from the general community through social media. Respondents could sign up for a session in the eye-tracking lab and one of them received a financial prize for participation through the draw at the end of the data collection. The data were collected in accordance with the ethical standards of the institutional research committee and the 1964 Helsinki declaration and its later amendments as well as comparable ethical standards.

\section{Procedure}

After completing the written online consent form and providing socio-demographic data, participants were shown photos representing happiness on the screen. Each happy expression ( 6 original color version photos) appeared in the middle of a black screen for 5 seconds in 
random order. The respondents were then asked to enter their free answer (to the question: "What emotion have you seen?") on the computer without any time limit. We did not analyze the emotion identification further as our goal was to detect scanning patterns for happy faces in relation to self-criticism and self-reassurance and, therefore, the question was only used to help participants to concentrate on the pictures more. They were also instructed that once they had pressed the confirm button, the next photo would automatically appear on the screen. After this identification procedure, participants were asked to complete an online version of The Forms of Self-Criticising/Attacking and Self-Reassuring Scale (FSCRS; Gilbert, Clarke, Hempel, Miles, \& Irons, 2004, translated into Slovak by Halamová, Kanovský, \& Pacúchová, 2017).

\section{Apparatus}

Tobii X2 60 eye-trackers with an I-VT Fixation Filter (Olsen \& Matos, 2012) were used to track the participant's gaze. The VelocityThreshold Identification (I-VT) fixation classification algorithm measures the participant's immediate emotional response. The minimum fixation duration was set to $70 \mathrm{~ms}$; shorter fixations were discarded. The monitor measured 52.5 $x 32.5 \mathrm{~cm}$, and the respondent's chair was situated $60 \mathrm{~cm}$ away from it. The visual angle of the monitor screen was $46.86^{\circ}$. According to previous studies with the same conditions, the visual angle of the facial emotions should be approximately $8^{\circ}$ (see Henderson, Williams, \& Falk, 2005) so it simulates the real situation of identifying emotions on human faces. All the photos used in our research measured $5.8 \mathrm{~cm} \times 8.7 \mathrm{~cm}$ (width $\times$ height), with a resolution of $211 \times 317$ pixels. The calibration was performed before each data collection and Tobii Studio software was used to present the stimuli and collect the eye-tracking data. Three areas of interest (AOI) were identified for each emotional picture: Area of the Eyes, the Area around the Eyes and the Area of the Lips.

\section{Materials}

Umeå University Database of Facial Expressions. The criteria for selecting the set of static images (photographs) of human faces expressing happiness were a good proportional representation of gender and age (the database contains younger and older respondents) and validity (a high percentage of people recognize the emotions in the database). After a thorough selection process, the Umeå University Database of Facial Expressions (Samuelsson, Jarnvik, Henningsson, Andersson, \& Carlbring, 2012) was selected for use in our study. We selected six photos of happiness that featured both men and women in three age groups (aged about 25 years old, 45 years old, and 65 years old). The models in the database had been instructed to wear no make-up but no further instructions were given regarding face-editing, so the images closely resembled the facial expressions seen in real life. No additional editing was performed other than resizing the photographs to the simulation reflecting the real-life recognition process (see Henderson, Williams, \& Falk, 2005). The mean hit rate (in \%) for the happy expressions in the database is $98 \%$, which indicates high prototypicality.

\section{Measure}

The Forms of Self-Criticising/Attacking \& Self-Reassuring Scale (FSCRS; Gilbert, Clarke, Hempel, Miles, \& Irons, 2004). The FSCRS is a 22-item self-report measure requiring participants to rate a selection of positive and negative statements on a 5-point Likert scale ranging from "Not at all like me." to "Extremely like me." Items include "I am easily disappointed with myself" and "I am gentle and supportive 
with myself'. Positive items reflect the ability to self-reassure (referred to as reassured self, RS) and negative items indicate self-critical thoughts and feelings (split into the subscales of Inadequate Self (IS); and Hated Self (HS). Results from different countries (e.g., Castilho, Pinto-Gouveia, \& Duarte, 2015; Kupeli, Chilcot, Schmidt, Campbell, \& Troop, 2013) including Slovakia (Halamová, Kanovský, \& Pacúchová, 2017) show that the FSCRS has good reliability and validity properties. The scale has been validated cross-culturally using 13 different nonclinical samples (Halamová et al., 2018), and the original three-factored solution (distinguishing between Inadequate Self and Hated Self) had an acceptable fit.

The outcome variable is Total Fixation Duration (TFD, also known as total dwell time, total viewing time, cumulative dwell time, gaze duration, etc.) and is measured in relation to the predefined Areas of Interest (AOI). TFD should be sensitive to slow and long-term cognitive processes (Holmqvist et al., 2011). According to Henderson and Hollingworth (1999, p. 252) there is "a clear effect of the meaning of a scene region on gaze duration in that region, but a less clear effect on first fixation duration". The relationship between attentional allocation and gaze duration is discussed in Eisenbarth and Alpers (2011). If proportion of gaze duration is used instead of TFD, linear-model statistical analyses can be misleading. Beta regression models are more appropriate for proportions, (Ferrari \& Cribari-Neto, 2004), although repeated measures ANOVA (RMANOVA) have been used for proportions in some studies (e.g., Farzin, Rivera, \& Hessl, 2009).

\section{Data Analyses}

We performed our analysis using the R environment for statistical computing version 3.4.0 (R Core Team, 2017), primarily the $l m e 4$ package (Bates, Maechler, Bolker, \& Walker, 2015).
We first tested for potential multicollinearity by using the Variance Inflation Factor (VIF), and afterwards we used the Generalized Linear Mixed-effect Model (GLMM). The dependent variable Total Fixation Duration (TFD) in seconds or milliseconds was measured for three Areas of Interest (AOI) using the set of stimuli (photos of human faces expressing happiness presented to all participants). The AOIs were defined as the Area of the Eyes, the Area around the Eyes, and the Area of the Lips. The stimuli represented three age categories (young, middle, and old) and the two sexes (male and female). This meant there were two levels of independent variables to be analyzed. For the first level, repeated measurements were taken for each participant. We took into account three mutually crossed within-subject factors: age and sex of the stimulus; and the Areas of Interest (AOI) for each stimulus. The covariates at the second level described the between-subject variation. The participant variable (ID) was a random factor, whereas the between-subject covariates (the questionnaire scores) were treated as fixed factors.

The first step was to detect any potential multicollinearity among the questionnaire scores. The VIF (Variance Inflation Factor) was calculated using the usdm package (Babak, 2015 ) in an attempt to detect multicollinearity. No multicollinearities were found among the FSCRS subscales (VIF for IS $=1.671, \mathrm{HS}=1.836$, $\mathrm{RS}=1.130)$ so they could be included in the model as between-subject covariates.

In the second step, we applied the Generalized Linear Mixed-effect Model (GLMM, see for example Lo \& Andrews, 2015). The response variable (Total Fixation Duration) had a highly skewed distribution and did not allow negative values, so models based on normal distribution were statistically inappropriate. There are ways to address these problems. One is to use a natural logarithm transformation of TFD (see for example Häikiö \& Vainio, 2018; Indrarathne, 
Ratajczak, \& Kormos, 2018). However, log-transformed TFDs are very difficult to interpret and it is hard to compare the results with those based on raw fixation times. This problem can be solved by using GLMM as it specifies the distribution of the dependent variable describing the plausible processes underlying the observed data (Lo \& Andrews, 2015). For variables such as duration, waiting time, and time between some events, gamma regression with the inverse link function is often used (for details, see Hogg \& Craig, 1978). For Total Fixation Duration (TFD), we modeled the average time between arriving at a particular AOI and skipping to another place. The average "skipping pace" varies with the individual.

As stated above, the dependent variable was Total Fixation Duration (TFD) measured in seconds. Because each participant viewed the same set of stimuli (i.e., pictures of human faces of varying age and sex) and because we defined the same three AOIs on each face, our data revealed the following structure: the sex and age of the stimuli, and the AOI were considered to be within-subject factors entered into the model as fixed effects. The participant identifier (ID) was included as a random effect in the model. Covariates, that is scores on dimensions of the FSCRS questionnaire (Inadequate Self, Hated Self, Reassured Self), were also kept as fixed effects. Our hypotheses (given in the Hypotheses section) concern the interaction between the self-reassurance and self-criticism measures and the AOI. Because we did not consider the sex and age of the stimuli to be relevant factors, we did not include them in the models.

To perform the GLMM analyses we used lme 4 (Bates, Maechler, Bolker, \& Walker, 2015) and to display the effects we used the effects package (Fox, 2003), both in the statistical environment R (R Core Team, 2018). As fixed effects, we entered the FSCRS subscale scores in an interaction with the Areas of Interest (AOI). As ran- dom effects, we used intercepts for participants. The R code syntax for the model was:

fm $4<$-glmer(TFD $\sim$ (FSCRS_IS + FSCRS_HS + FSCRS_RS $)^{*} \mathrm{AOI}+(1 \mid \mathrm{id}), \overline{\text { data }}=\mathrm{x}$, family $=$ Gamma(link="inverse"), control=glmerControl (optimizer="bobyqa", optCtrl = list $($ maxfun $=$ 100000)))

$\mathrm{R}^{2}$ ('variance explained') statistics were used to measure the effect size of the model. However, with GLMMs, estimating the $\mathrm{R}^{2}$ is far from trivial and there is no consensus as to the most appropriate definition of $\mathrm{R}^{2}$ statistics in relation to mixed-effect models (Edwards et al., 2008; Nakagawa \& Schielzeth, 2013; LaHuis, Hartman, Hakoyama, \& Clark, 2014; Jaeger, Edwards, Das, $\&$ Sen, 2016). Although several methods for estimating the coefficient of determination $\left(\mathrm{R}^{2}\right)$ for mixed-effect models are available in the r2glmm package (Jaeger, 2017), only the Standardized Generalized Variance approach (SGV) can be used with GLMMs (Jaeger, Edwards, Das, \& Sen 2016). This package first estimates the model parameters using the penalized quasilikelihood, and then estimates the $\mathrm{R}^{2}$ statistics for the model as well as the semi-partial $\mathrm{R}^{2}$ for the fixed effects. Graphs were obtained by plotting the marginal effects using R package jsPlot (Lüdecke, 2018).

\section{Results}

The descriptive statistics for the FSCRS subscale scores and Total Fixation Duration (TFD), mutual correlations among the covariates (i.e., FSCRS subscale scores) as well as the Pearson product-moment correlations between the covariates and the mean TFDs for particular areas of interest (AOIs) are shown in Tables 1.1, 1.2, and 1.3. The TFD plots are given for various combinations of level of fixed effect in relation to level of Inadequate Self, Hated Self, and Reassured Self for the three AOIs: the eyes, lips, and area around the eyes (Figure 1, Figure 2, and Figure 3). 
Table 1.1 Descriptive statistics for FSCRS subscale scores and for the Total Fixation Duration (TFD) in milliseconds

\section{Trimmed}

n Mean SD Median Mean MAD Min Max Skewness Kurtosis SE $(\operatorname{tr}=.2)$

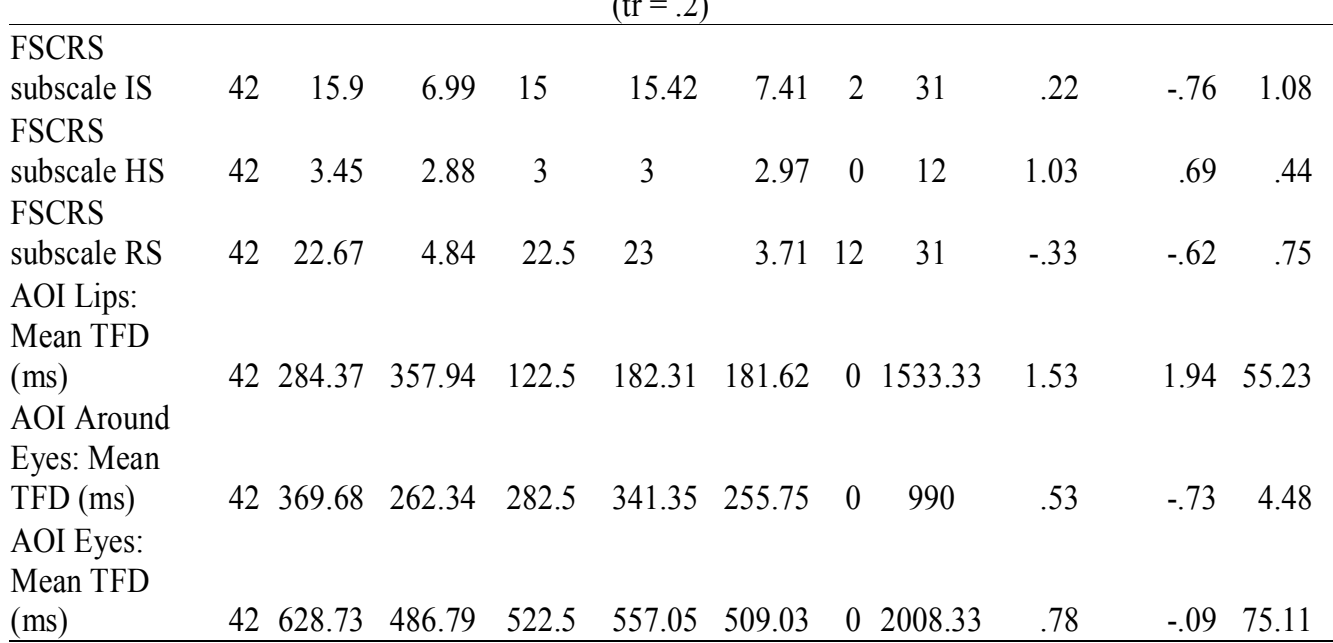

Note. FSCRS - The Forms of Self-Criticising/Attacking \& Self-Reassuring Scale, IS - Inadequate Self, HS - Hated Self, RS - Reassured Self, TFD - Total Fixation Duration, AOI - Areas of Interest.

Table 1.2 Pearson product-moment correlations between the FSCRS subscale scores

\begin{tabular}{lccc}
\hline & FSCRS subscale IS & FSCRS subscale HS & FSCRS subscale RS \\
\hline FSCRS subscale IS & 1 & $.568^{* *}$ & -.129 \\
FSCRS subscale HS & $.568^{* *}$ & 1 & -.278 \\
FSCRS subscale RS & -.129 & -.278 & 1 \\
\hline
\end{tabular}

Note. ${ }^{* *}$ - Correlation is significant at the .01 level (2-tailed). FSCRS - The Forms of SelfCriticising/Attacking \& Self-Reassuring Scale, IS - Inadequate Self, HS - Hated Self, RS Reassured Self, TFD - Total Fixation Duration, AOI - Areas of Interest.

Table 1.3 Pearson product-moment correlations between the FSCRS subscale scores and the mean Total Fixation Duration (TFD) for particular AOI

\begin{tabular}{lccc}
\hline & AOI Lips: & AOI Around Eyes: & AOI Eyes: \\
& Mean TFD & Mean TFD & Mean TFD \\
\hline FSCRS subscale IS & .264 & $.341^{*}$ & -.011 \\
FSCRS subscale HS & .022 & .051 & -.155 \\
FSCRS subscale RS & -.084 & .148 & -.132 \\
\hline
\end{tabular}

Note. $*$ - Correlation is significant at the .05 level (2-tailed). FSCRS - The Forms of SelfCriticising/Attacking \& Self-Reassuring Scale, IS - Inadequate Self, HS - Hated Self, RS - Reassured Self, TFD - Total Fixation Duration, AOI - Areas of Interest. 


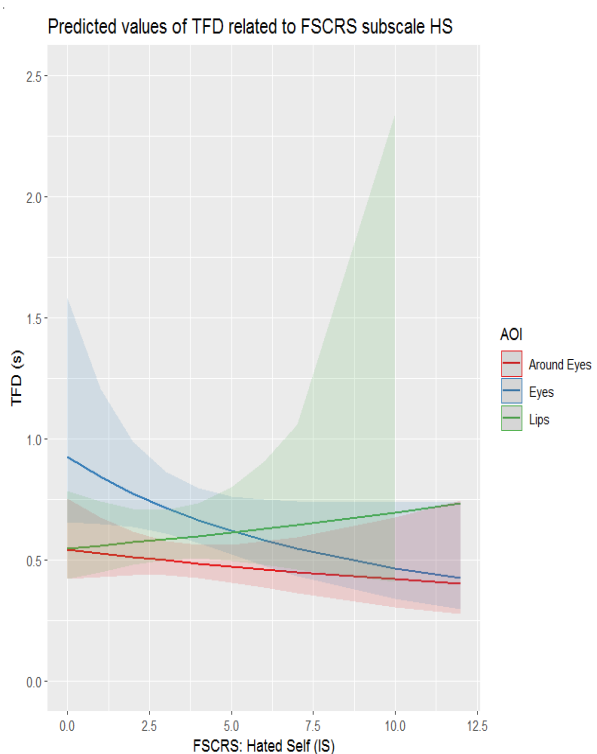

Figure 1 The plots of TFD for Hated Self ofFSCRS

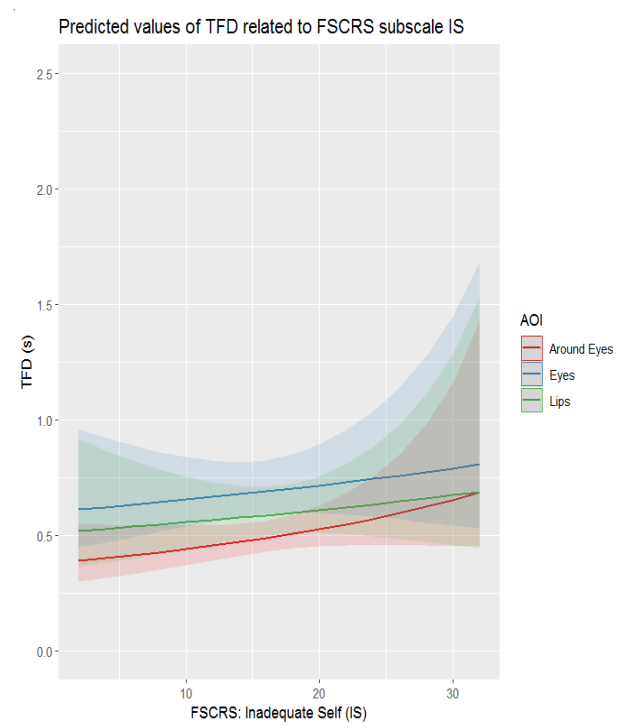

Figure 2 The plots of TFD for Inadequate self of FSCRS

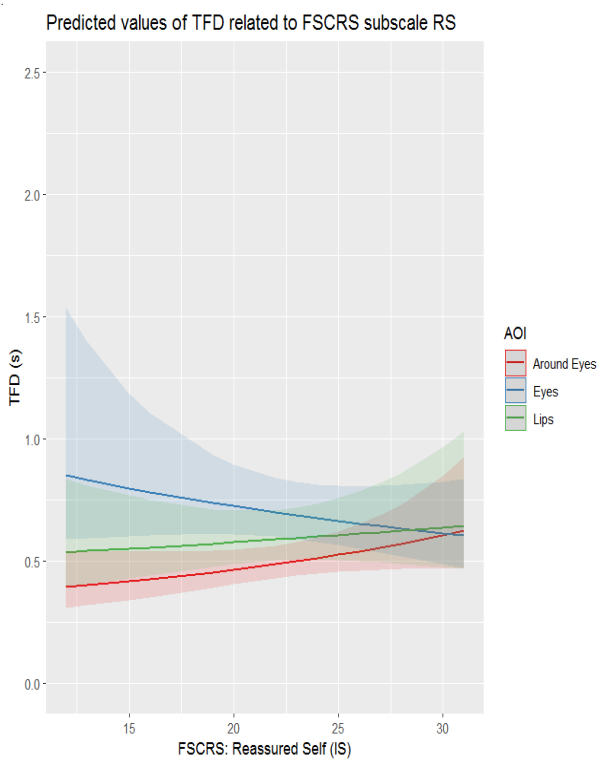

Figure 3 The plots of TFD for Reassured self of FSCRS

As explained above, the Gamma distribution is a much more appropriate model for the TFD distribution. After the Generalized Linear Mixedeffect Model based on Gamma distribution was fitted, the residuals followed the normal distribution sufficiently for practical needs. The overall fit of the model was low (estimated $\mathrm{R}^{2}=.126$ with $95 \%$ CI $[.09, .212])$.

The information criteria for the multilevel model were as follows: $\mathrm{AIC}=483$; $\mathrm{BIC}=54.4$; the intraclass correlation $\mathrm{ICC}=.264$. The estimated $t$-values in the mixed-effect regression analysis (Table 2) show that the "Eyes" AOI was a significant predictor of Total Fixation Duration (the negative estimate of the Beta value indicates the fixation duration was longer than for the "Lips" AOI). Also, the estimate of the semipartial $\mathrm{R}^{2}=.015$ (95\% CI [.001, .049]) revealed the strongest partial effect. As far as our hypotheses are concerned, the most inter- 
esting results relate to the interaction between the various FSCRS dimensions and AOIs.

A rising score on the Hated Self(HS) subscale was generally negatively correlated to Total Fixation Duration on the eye region $(\beta=.146, p=$ .018 ; semi-partial $\left.\mathrm{R}^{2}=.009\right)$. A similar but weaker effect was observed for the relation between Hated Self score and Total Fixation Duration for the area around the eyes. However, there was no relationship between Total Fixation Duration for the lips and Hated Self score. This finding supports the first hypothesis, but only for the Hated Self dimension. Participants scoring higher on Inadequate Self generally fixated more on all the areas of the face. But this effect was very weak and statistically insignificant $(\beta$ $=-.016, p=.544$; semi-partial $\left.\mathrm{R}^{2}=.001\right)$. This part of the first hypothesis was therefore not supported by the empirical findings.

Participants scoring higher on Reassured Self tended to spend less time fixating on the eyes than on the area of the lips $(\beta=.042, p=.082$;

Table 2 Mixed effect regression analysis

Generalized Linear Mixed-effect Model fit by maximum likelihood (Laplace Approximation)

['glmerMod']. Family: Gamma (inverse)

Formula: TFD $\sim($ FSCRS_IS + FSCRS_HS + FSCRS_RS $) *$ AOI + (1 $\mid$ id $)$

Control: glmerControl(optimizer = "bobyqa". optCtrl = list $(\operatorname{maxfun}=1 \mathrm{e}+05))$

$\begin{array}{lcccc}\text { AIC } & \text { BIC } & \text { LogLik } & \text { Deviance } & \text { Df.resid } \\ 483 & 54.4 & -227.5 & 455 & 433\end{array}$

Scaled residuals

$\begin{array}{ccccc}\text { Min } & 1 \mathrm{Q} & \text { Median } & 3 \mathrm{Q} & \text { Max } \\ -1.335 & -.757 & -.230 & .587 & 3.854\end{array}$

Random effects:

$\begin{array}{lccc}\text { Groups } & \text { Name } & \text { Variance } & S D \\ \text { id } & \text { (Intercept) } & .168 & .410 \\ \text { Residual } & & .468 & .684 \\ \text { ICC } & & .264 & \end{array}$

Number of obs: 447 . groups: id. 40

Fixed effects:

(Intercept)

FSCRS subscale IS

FSCRS subscale HS

FSCRS subscale RS

AOI Around Eyes

AOI Eyes

FSCRS subscale IS $\times$ AOI Around Eyes

FSCRS subscale IS $\times$ AOI Eyes

\begin{tabular}{ccccccc}
$\begin{array}{c}\text { Estimate } \\
\text { (Beta) }\end{array}$ & $\mathrm{SE}$ & $t$ & $p$ & $\mathrm{R}^{2}$ & $\begin{array}{c}\text { lower } \\
\mathrm{CL}\end{array}$ & $\mathrm{CL}$ \\
2.456 & .765 & 3.212 & $.001^{* *}$ & & & \\
-.016 & .026 & -.606 & .544 & .001 & 0 & .019 \\
-.039 & .073 & -.529 & .597 & .001 & 0 & .019 \\
-.016 & .030 & -.549 & .583 & .001 & 0 & .019 \\
1.136 & .823 & 1.380 & .168 & .007 & 0 & .033 \\
-1.726 & .587 & -2.942 & $.003 * *$ & .015 & .001 & .049 \\
-.021 & .026 & -.813 & .416 & .002 & 0 & .021 \\
.003 & .021 & .121 & .904 & 0 & 0 & .014 \\
\hline
\end{tabular}

Table 2 continues 
Table 2 continued

Table 2 Mixed effect regression analysis

\begin{tabular}{lccccccc}
\hline & $\begin{array}{c}\text { Estimate } \\
\text { (Beta) }\end{array}$ & SE & $t$ & $p$ & $\mathrm{R}^{2}$ & CL & CL \\
\hline FSCRS subscale HS × AOI Around Eyes & .092 & .072 & 1.267 & .205 & .004 & 0 & .026 \\
FSCRS subscale HS × AOI Eyes & .146 & .062 & 2.358 & $.018^{*}$ & .009 & 0 & .039 \\
FSCRS subscale RS × AOI Around Eyes & -.034 & .030 & -1.119 & .263 & .004 & 0 & .026 \\
FSCRS subscale RS $\times$ AOI Eyes & .042 & .024 & 1.739 & .082 & .005 & 0 & .03 \\
$\mathrm{R}^{2}$ for model & & & & & .126 & .09 & .212 \\
\hline
\end{tabular}

Note. 1Q - first quartile of the residuals, $3 \mathrm{Q}$ - third quartile of the residuals, AIC - Akaike's Information Criterion, AOI - Areas of Interest, BIC - Bayesian Information Criterion, CL - Limit of the $95 \%$ confidence interval, Df.resid - residual degrees of freedom, FSCRS - The Forms of Self-Criticising/ Attacking and Reassuring Scale, HS - Hated Self, ICC - Intraclass correlation coefficient, IS - Inadequate Self, LogLik - Logarithm of likelihood, Min - Minimum of the residuals, Max - Maximum of the residuals, $p-\mathrm{p}$-value for the null hypothesis that the estimated regression model parameter is equal $0, \mathrm{R}^{2}$ - squared semi-partial correlation coefficient used as an effect size, RS - Reassured Self, SE - Standard Error of the regression model parameter estimate, $t$-Student's test statistics.

semi-partial $\left.\mathrm{R}^{2}=.005\right)$. They spent more time fixating on the area around the eyes, but this effect was not statistically significant $\beta=-.003$, $p=.263$; semi-partial $\mathrm{R}^{2}=.004$. Consequently, the data did not support our second hypothesis.

\section{Discussion}

The results of our eye-tracking study indicate that scanning patterns differ in people recognizing the facial expression of happiness according to level of self-criticism and level of self-reassurance. Our findings allow us to partially accept our first hypothesis that self-criticism is related to avoidance of direct eye contact. But it is so only for people who have the more pathological form of self-criticism, Hated Self, and not for people with Inadequate Self. Hated Self is an indicator of the need to hurt oneself through self-contempt and self-hate (Gilbert et al., 2004). Thus, the results are in line with the assumption that a more aggressive or disgust form of self-criticism is related to eye avoidance when recognizing the emotion of happiness in another person.

The results are consistent with previous research findings obtained using constructs such as shyness (Wang, Short, \& Fu, 2012), neuroticism (Perlman et al., 2009), anxiety (Wang \& Yue, 2011), social anxiety (Daly, 1978; Farabee, Holcom, Ramsey, \& Cole, 1993), and empathy (Cowan, 2015) and emphasize the avoidance of fixating on some areas of the face, in some cases directly on the eye area (Cowan, 2015; Wang, Short, Hu \& Fu, 2012). In contrast to these findings, higher Inadequate Self score tended to be related to fixating more on all the areas of the faces analyzed (the eyes, outside the eyes as well as the lips) but not to a statistically significant degree. Thus, the Hated Self seems to be a significant form of self-criticism in exploring the biases in happy faces scanning.

We were unable to confirm the second hypothesis that self-reassurance would be related to concentration more on the eye area than the lip area when recognizing happy expressions. Although, not a statistically significant finding 
it is interesting that people with a higher level of self-reassurance tended to spend more time fixating on the area around the eyes where the happiness wrinkles known as crow's feet are located. A happy face may naturally attract more attention towards the lip area because the lips may be crucial to recognizing the emotion of joy (Schurgin et al., 2014; Blais et al., 2012). Nevertheless, while self-reassured people recognize the expression using an evident cue in the lower parts of the face, it seems they specifically check the region around the eyes that may hide information as to whether the person is truly happy (Manera et al., 2011; Williams et al., 2011), as conveyed by the Duchenne smile (Williams et al., 2001). Definitely, this tendency should be further tested in future research as it might be used for future diagnostic purposes.

We are aware of several limitations of our study. The research was conducted in an artificial laboratorysetting, and this mayhave created specific conditions, as the participants did not have to simulatereal interaction with emotional faces in the usual social environment. Another limitation is the convenience sample of 42 participants, mainly consisting of young respondents recruited from a communityof the nonclinical population. As the Hated Self seems to be significant predictor of scanning patterns in self-critical sample, further research should focus on selection of participants with particularly high level of Hated Selfor Reassured Selfor even participants with severe clinical diagnoses. Then, the results might bedemonstrated even more clearlyand that would be very meaningful for further diagnostic purposes. Even though the size stimuli of 6happy expressions in our study was as it is recommended by previous research (Henderson, Williams, \& Falk, 2005), we might extend their size in future research to test the effect of their size on the results. Facial-expression databases are a standard instrument for measuring facial-emotion recognition(e.g., Steele et al., 2008) because in general, photos of emotional faces elicit a higher subjec- tive response than videos due to their projective nature (see e.g., Poláčková Šolcová, \& Lačev, 2017). However, further research may compare the biases comparing static and dynamic stimuli among self-critical individuals to explore the differences in various conditions of viewing. In addition, while the happy faces' scanning was our first interest to explore, other primary emotions can also be relevant for self-criticism and self-reassurance(e.g., angryor sad stimuli). This should be addressed in future research.

Nonetheless, the results are promising in terms of assessing people who score high on Hated Self and in distinguishing them from people with a less pathological form of self-criticism, represented by their Inadequate Self score on the FSCRS. Finally, the study consists of a single experiment using happy faces only, and it is a simple preliminary study that needs to be extended in an additional study to test all the primary emotions.

\section{Conclusion}

Our study on scanning patterns and recognition of the facial emotion of happiness has shown that these differed between people according to level and form of self-criticism and self-reassurance. Participants with a higher Hated Self score focused significantly less on the eyes and the areas around the eyes, while participants with a higher Inadequate Selfscoretended to fixate more on all the areas of the person's face. Self-reassured participants tended to concentrate more on the area around the eyes when recognizing happy facial expressions. These findings deserve further research and the intention is to investigate all the primaryemotions. They could potentially be exploited for potential diagnostic purposes in the future. As this study has suggested, eyetracking is a more objective method than self-report questionnaires and as such is a promising method for research on self-criticism and selfreassurance. 


\section{References}

Adams, R., \& Kleck, R. (2003). Perceived gaze direction and the processing of facial displays of emotion. Psychological Science, 14, 644-647. doi: 10.1046/j.0956-7976.2003.psci_1479.x

Allan, S., \& Gilbert, P. (1997). Submissive behavior and psychopathology. British Journal of Psychopathology, 36, 467-488. doi: 10.1111/j.2044-8260. 1997.tb01255.x

Babak, N. (2015). usdm: Uncertainty analysis for species distribution models. $R$ package version 1.1-15. Retrieved from https://CRAN.R-project.org/package $=$ usdm

Bates, D., Maechler, M., Bolker, B., \& Walker, S. (2015). Fitting Linear Mixed-Effects Models using lme4. Journal of Statistical Software, 67(1), 1-48. doi:10.18637/jss.v067.i01

Blais, C., Roy, C., Fiset, D., Arguin, M., \& Gosselin, F. (2012). The eyes are not the window to basic emotions. Neuropsychologia, 50, 2830-2838. doi: 10.1016/j.neuropsychologia.2012.08.010

Blatt, S. J., Quinlan, D. M., Chevron, E. S., McDonald, C., \& Zuroff, D. (1982). Dependency and self-criticism: Psychological dimensions of depression. Journal of Consulting and Clinical Psychology, 50(1), 113-124. doi: http://dx.doi.org/10.1037/0022006 X.50.1.113

Calvo, M. G, \& Lundqvist, D. (2008). Facial expressions of emotion (KDEF): Identification under different display-duration conditions. Behavior Research Methods, 40(1), 109-15. doi: 10.3758/ BRM.40.1.109

Castilho, P., Pinto-Gouveia, J., \& Duarte J. (2015). Exploring self-criticism: Confirmatory factor analysis of the FSCRS in clinical and nonclinical samples. Clinical Psychology \& Psychotherapy, 22(2), 153164. doi: $10.1002 / \mathrm{cpp} .1881$.

Cowan, D. G. (2015). The empathic gaze and how to find it: Eye-gaze behaviour to expressions of emotion (Bachelor thesis). The University of Queensland, Australia.

Daly, S. (1978). Behavioural correlates of social anxiety. British Journal of Clinical Psychology, 17, 117120. doi: $10.1111 / \mathrm{j} .2044-8260.1978 . t b 00252 . \mathrm{x}$

Ekman, P. (1972). Universal and cultural differences in facial expression of emotion. In J. R. Cole (Ed.), Nebraska Symposium on Motivation, 1971 (Vol. 19, pp. 207-283). Lincoln, NE: Nebraska University Press.

Edwards, L. J., Muller, K. E., Wolfinger, R. D., Qaqish, B. F., \& Schabenberger, O. (2008). An R2 statistic for fixed effects in the linear mixed model. Statistics in Medicine, 27(29), 6137-6157. doi: 10.1080/ 02664763.2016 .1193725

Eisenbarth, H., \& Alpers, G. W. (2011). Happy mouth and sad eyes: Scanning emotional facial expressions. Emotion, 11(4), 860-865. doi: 10.1037/a0022758

Ekman, P. (1993). Facial expression and emotion. American Psychologist, 48(4), 384-392. doi: 0003066X/93/52:00

Ekman, P., \& Friesen, W. V. (1971). Constants across cultures in the face and emotion. Journal of Personality and Social Psychology, 17(2), 124-129.

Farabee, D. J., Holcom, M. L., Ramsey, S. L, \& Cole, S. G. (1993). Social anxiety and speaker gaze in a persuasive atmosphere. Journal of Research in Personality, 27, 365-376. doi: 10.1006/jrpe.1993.1025

Farzin, F., Rivera, S. M., \& Hessl, D. (2009). Brief report: Visual processing of faces in individuals with fragile X syndrome: An eye tracking study. Journal of Autism and Developmental Disorders, 39(6), 946952. doi: 10.1007/s10803-009-0744-1

Ferrari, S., \& Cribari-Neto, F. (2004). Beta regression for modelling rates and proportions. Journal of Applied Statistics, 31(7), 799-815. doi: 10.1080/ 0266476042000214501

Fox, J. (2003). Effect displays in R for Generalised Linear Models. Journal of Statistical Software, 8(15), 1-27. URL http://www.jstatsoft.org/v08/i15/

Gablíková, M., \& Strnádelová, B. (2016). Teachers' ability to detect student's facial expressions of emotion. In J. Halamová (Ed.), Komunitná psychológia na Slovensku 2016 (pp. 100-108). Bratislava: Univerzita Komenského v Bratislave vo Vydavatel'stve UK pre Ústav aplikovanej psychológie.

Gendron, M., Roberson, D., van der Vyver, J. M., \& Barrett, L. F. (2014). Perceptions of emotion from facial expressions are not culturally universal: Evidence from a remote culture. Emotion, 14(2), 25162. doi: $10.1037 / \mathrm{a} 0036052$

Gilbert, P. (2010). Training our minds in, with and for compassion. An introduction to concepts and compassion-focused exercises. Retrieved on 21.8.2016 from: http://wtm.thebreathproject.org/wp-content/ uploads/2016/03/COMPASSION-HANDOUT.pdf

Gilbert, P., \& Allan, S. (1994). Assertiveness, submissive behavior, and social comparison. British Journal of Clinical Psychology, 33, 295-306.

Gilbert, P., Baldwin, M. W., Irons, Ch., Bacus, J. R., \& Palmer, M. (2006). Self-criticism and Self-warmth: An imagery study exploring their relation do depression. Journal of Cognitive Psychotherapy, 20(2), 183-200. doi: 10.1891/088983906780639817

Gilbert, P., Clark, M., Hempel, S., Miles, J. N. V., \& Irons, C. (2004). Criticising and reassuring oneself: An exploration of forms, styles and reasons in female students. British Journal of Clinical 
Psychology, 43, 31-50. doi: 10.1348/ 014466504772812959

Goren, D., \& Wilson, H. R. (2006). Quantifying facial expression recognition across viewing conditions. Vision Research, 46, 1253-1262. doi: 10.1016/ j.visres.2005.10.028

Gotlib, I. H., Krasnoperova, E., Yue, D. N., \& Joormann, J. (2004). Attentional biases for negative interpersonal stimuli in clinical depression. Journal of $\mathrm{Ab}$ normal Psycholology, 113, 127-135. doi: 10.1037/ 0021-843X.113.1.121

Häikiö, T., \& Vainio, S. (2018). Syllables and inflectional morphemes in early Finnish readers: Evidence from eye-movements. Journal of Child Language, 1-19. doi: 10.1017/S0305000918000132

Halamová, J., Kanovský, M., Gilbert, P., Kupeli, N., Troop, N., Zuroff, D., Hermanto, N., Petrocchi, N., Sommers-Spijkerman, M., Kirby, J., Shahar, B., Krieger, T., Matos, M., Asano, K., Yu, F., \& Basran, J. (2018). The factor structure of the Forms of SelfCriticising/Attacking \& Self-Reassuring Scale in thirteen populations. Journal of Psychopathology and Behavioral Assessment, 40(4), 736-751. doi: 10.1007/s10862-018-9686-2

Halamová, J., Kanovský, M., \& Pacúchová M. (2017). Robust psychometric analysis and factor structure of the Forms of Self-criticizing/Attacking and Selfreassuring Scale. Československá Psychologie, 4, 456471.

Henderson, J. M., \& Hollingworth, A. (1999). Highlevel scene perception. Annual Review of Psychology, 50(1), 243-271.

Henderson, J. M., Williams, C. C., \& Falk, R. J. (2005). Eye movements are functional during face learning. Memory \& Cognition, 33, 98-106. doi: 10.3758/ BF03195300

Hess, U., Blairy, S., \& Kleck, R. E. (1997). The intensity of emotional facial expressions and decoding accuracy. Journal of Nonverbal Behavior, 21, 241257.

Hessels, R. S., Kemner, C., van den Boomen, C., et al. (2016). The area-of-interest problem in eyetracking research: A noise-robust solution for face and sparse stimuli. Behavior Research Methods, 48(4), 16941712. doi: 10.3758/s13428-015-0676-y

Hogg, R. V., \& Craig, A. T. (1978). Introduction to mathematical statistics, 4th edition (Section 3.3). New York: Macmillan.

Holmqvist, K., Nyström, M., Andersson, R., Dewhurst, R., Jarodzka, H., \& Van de Weijer, J. (2011). Eye tracking: A comprehensive guide to methods and measures. Oxford: Oxford University Press.

Indrarathne, B., Ratajczak, M., \& Kormos, J. (2018). Modelling changes in the cognitive processing of grammar in implicit and explicit learning conditions:
Insights from an eye-tracking study. Language Learning 8(3), 669-708. doi: 10.1111/lang.12290

Izard, C. E. (1971). The face of emotion. East Norwalk, CT: Appleton-Century-Crofts.

Jaeger, B. C., Edwards, L. J., Das, K., \& Sen, P. K. (2016). An R2 statistic for fixed effects in the generalized linear mixed model. Journal of Applied Statistics, 44(6), 1086-1105. doi: 10.1080/02664763. 2016.1193725

Jaeger, B. (2017). r2glmm: Computes $R$ Squared for Mixed (Multilevel) Models. $R$ package version 0.1.2. Retrieved from https:/CRAN.R-project.org/package $=\mathrm{r} 2 \mathrm{~g} 1 \mathrm{~mm}$

Jack, R. E., Garrod, O. G. B., Yu, H., Caldara, R., \& Schyns, P. G. (2012). Facial expressions of emotion are not culturally universal. Proceedings of the $\mathrm{Na}$ tional Academy of Sciences of the United States of America. 109(19), 7241-7244. doi: 10.1073/ pnas. 1200155109

Kupeli, N., Chilcot, J., Schmidt, U. H., Campbell, I. C., \& Troop, N. A. (2013). A confirmatory factor analysis and validation of the forms of Self-Criticism/ Reassurance Scale. British Journal of Clinical Psychology, 52(1), 12-25. doi: 10.1111/j.2044-8260. 2012.02042

LaHuis, D. M., Hartman, M. J., Hakoyama, S., \& Clark, P. C. (2014). Explained variance measures for multilevel models. Organizational Research Methods, 17(4), 433-451. doi: 10.1177/1094428114541701

Leppänen, J. M., \& Hietanen, J. K. (2004). Positive facial expressions are recognized faster than negative facial expressions, but why? Psychological Research, 69, 22-29. doi: 10.1007/s00426-003-0157-2

Lindquist, K. A., \& Barrett, L. F. (2012). A functional architecture of the human brain: Insights from emotion. Trends in Cognitive Sciences, 16(11), 533540. doi: $10.1016 / \mathrm{j}$.tics.2012.09.005

Lo, S., \& Andrews, S. (2015). To transform or not to transform: Using generalized linear mixed models to analyse reaction time data. Frontiers in Psychology, 6, 1171. doi: 10.3389/fpsyg.2015.01171

Lüdecke, D. (2018). sjPlot: Data visualization for statistics in social science. (R package version 2.6.1) Retrieved from https://CRAN.R-project.org/package $=$ sjPlot

Manera, V., Del Giudice, M., Grandi, E., \& Colle, L. (2011). Individual differences in the recognition of enjoyment smiles: No role for perceptual-attentional factors and autistic-like traits. Frontiers in Psycholology, 2, 143. doi: 10.3389/fpsyg.2011. 00143

Matsumoto, D. (2001). Culture and emotion. In D. Matsumoto (Ed.), The handbook of culture and psychology (pp. 171-194). New York: Oxford University Press. 
McEwan, K., Gilbert, P., Dandeneau, S., Lipka, S., Maratos, F., Paterson, K. B., \& Baldwin, M. (2014). The processing of compassionate and critical facial expressions. PLos One, 9(2), 1-8. doi: 10.1371/ journal.pone.0088783.

Milders, M., Hietanen, J. K., Leppänen, J. M., \& Braun, M. (2011). Detection of emotional faces is modulated by the direction of eye gaze. Emotion, 11(6), 1456-1461. doi: 10.1037/a0022901

Nakagawa, S., \& Schielzeth, H. (2013). A general and simple method for obtaining R2 from generalized linear mixed-effects models. Methods in Ecology and Evolution, 4(2), 133-142. doi: 10.1111/J.2041210x.2012.00261.X

Olsen, A., \& Matos, R. (2012). Identifying parameter values for an I-VT fixation filter suitable for handling data sampled with various sampling frequencies. In C. H. Morimoto, H. O. Istance, S. N. Spencer, J. B. Mulligan, \& P. Qvarfordt (Eds.), Proceedings of the 2012 symposium on eye tracking research and applications, ETRA 2012 (pp. 317-320). New York: ACM.

Palermo, R., \& Coltheart, M. (2004). Photographs of facial expression: Accuracy, response times, and ratings of intensity. Behavior Research Methods, Instruments, \& Computers, 36, 634-638. doi: 10.3758/ BF03206544

Perlman, S. B., Morris, J. P., Vander Wyk, B. C., Green, S. R., Doyle, J. L., et al. (2009). Individual differences in personality predict how people look at faces. PLos One, 4(6): e5952. doi: 10.1371/ journal.pone.0005952

Pinheiro, J., Bates, D., DebRoy, S., Sarkar, D., \& R Core Team (2017). nlme: Linear and Nonlinear Mixed Effects Models. R package version 3.1-131. Retrieved from https://CRAN.R-project.org/package =nlme

Poláčková Šolcová, I., \& Lačev, A. (2017). Differences in male and female subjective experience and physiological reactions to emotional stimuli. Inter- national Journal of Psychophysiology, 117, 75-82. doi: $10.1016 /$ j.ijpsycho.2017.04.009.

R Core Team (2018). R: A language and environment for statistical computing. R Foundation for Statistical Computing, Vienna, Austria. Retrieved from http:/ /www.R-project.org/.

Russell, J. A. (1994). Is there universal recognition of emotion from facial expression? A review of crosscultural studies. Psychological Bulletin, 115, 102-141.

Samuelsson, H., Jarnvik, K., Henningsson, H., Andersson, J., \& Carlbring, P. (2012). The Umeí University database of facial expressions: A validation study. Journal of Medical Internet Research, 14(5), 136. doi: 10.2196/jmir.2196

Schurgin, M. W., Nelson J., Iida S., Ohira, H., Chiao, J. Y., \& Franconeri S. L. (2014). Eye movements during emotion recognition in faces. Journal of Vision 14(13), 1-16. doi: 10.1167/14.13.14

Schultheiss, O. C., \& Hale, J. A. (2007). Implicit motives modulate attentional orienting to facial expressions of emotion. Motiv Emotion 31, 3-24. doi: 10.1007/s1 1031-006-9042-9.

Terburg, D., Aarts, H., \& van Honk, J. (2012). Memory and attention for social threat: Anxious hypercodingavoidance and submissive gaze aversion. Emotion, 12(4), 666-672. doi: 10.1037/a0027201

Wang, Q., Hu, C., Short. L. A., \& Fu, G. (2012). The influence of shyness on the scanning of own- and other-race faces in adults. PLoS ONE, 7(12). doi: 10.1371/journal.pone.0052203

Wang, L., \& Yue, X. (2011). Attention bias during processing of facial expressions in trait anxiety: An eye-tracking study. 2011 International Conference on Electronics and Optoelectronics (ICEOE 2011). doi: 10.1109/ICEOE.2011.6013117

Williams, L. M., Senior, C., David, A. S., Loughland, C. M., \& Gordon, E. (2001). In search of the "Duchenne smile": Evidence from eye movements. Journal of Psychophysiology, 15, 122-127. doi: 10.1027// 0269-8803.15.2.122 